recommondation of a more frequent use of the stethoscope, as having a most important bearing upon the detection and treatment of the disease under consideration. As a means of diagnosing pulmonary disease, and especially pneimonia, on board ship, this instrument is less generally used than it ought to be, becanse it is alleged that the various lond noises at sea must drown such feeble sounds as those which proceed from the delicate texture of the lungs. This is a ready and an easy excuse for indolence, but it is entirely an erroneuus allegation. The sounds of a diseased lung are not so inarticulate but that they way be discovered by a litile practice even in the howling of a fiale, and in spite of the universal creaking at such times. Under such circumstances, refinements in explor.ation cannot be accomplished, but enough may be done for all practical purposes. On all occasions, therefore, this aid to diasnosis will be found as valuable on shipboard as on shore. The use of the instrument might be first practised driring the morning and evening musters, or at night, shortly after the people have retired to bed. At such times comparative quiet reigns thronghout the ship, and it is quite possible then to detect even a slight inequality in the vesicular murmur; and the small crepitation, bronchophony, and tubular breathing of an inflamed and infiltrated lung will be very readily heard, and, once heard, cannot be confounded with any other sounds whatever. Without the aid of the stethescope it is difficult to tell whether one lung is affected or both, and quite impossible to discover accurately the extent of the inflammation in either, with its daily increase or decease, by an exact knowledge of which our treatment must in some measure be regulated. Without its aid it is impossible to trace out the linits of the disease. To mark these limits with ink is, moler many circumstances, an excellent ailjutor memorice, and an important guide in ascertaining its advance or retrogression. Amongst our hardy seamen acute pulmonic inflammation, unless early discovered and energetically treated, proceeds rapidly to a fatal termination. The speedy detection of impaired murmur and small crepitation is therefore of vital importance. Upon this discovery, and his subjection to active measures during the first forty-eight hours, the safety of the patient generally depends. How important is it therefore to familiarise ourselves winh the use of this valuable adjuvant to diagnosis!

Very good reasons can be shown for urging an application of the stethoscope, during cold and wet weather, to the chests of such as present themselves complaining of shivering, headache, and other symptoms of a febrile character. In doing so, it should be borne in mind that pulmonary disease of a low cachectic kind, such as tuberculosis and the pmemnonia of typhus, nsually first appears in the upper lobes, while acute puenmonia has a very marked preference for the lower lobes, and the pusterior and lateral portions of these. The abnormal somds of this disease onght therefore to be first searched for in the posterior and lateral regions of the chest, and near the ingles of the seapula. Pneumonia is invariably ushered in by fever, and it not unfrequently happens that the first day or two passes without any one characteristic symptom of the disease showing itself. Hince the value of the stethoscope, as recommended above, during any continuance of cold and wet weather. An ontline of the general features of many such cases admitted into this hospital, from notes taken at the time of their occurrence, will tend to confirm what has just been written; axd with this outline I shall conclude the present paper.

They generally commencel with chills and shivering, lasting many hours. A condition of febrile reaction, heat, thirst, and headache succeeded, but did not terminate in diaphoresis. It was not unusual for this condition to continue without any pathognomonic symptom, and in soice of the cases there was no congh, and no rusty sputa, no dyspnœa, and little distress during the first two days, while the disease was making its insidious progress. There was in truth little to be seen by a common olyserver beyond what might be looked for in an attack of simple fever, and the writien "cases" brought with the jatients to hospital often desimated thew as fever. In a $f \in w$ of the cases only was there a slight tinge of red in the cheeks; not a congested flush, but yet enough to raise suspicion in the mind of a cautious observer that there might be some impediment to the free circulation in the lings. In by far the largest proportion the inflammatory engorgement first occupied the posterior part of the lower lobes of one or both lungs; and aithough the usual distinguishing symptoms were at first wanting, the physical signs of the disease were readily detected on applying the stethoscope to the postericr and lateral regions of the chest. Exploration confined to the anterior regions of this cavity led to no discovery. The murmur was exaggerated or puerile, as it is called, becanse the anterior portions of the lung, as yet maffectel, were labouring to perform the work of the whole. But it is sometimes not so easy as may be supposed, to distinguish the difference between that which is called puerile respiration and the healthy murmur of certain strong men used to hard labour. Therefore examination of the anterior regions, although valuable by contrast with the posterior, led to nothing conclusive. But on applying the instrument to the right quarter, the extent and much of the engorgement were realily traced on either side of the spine by the vocal resonance, bronchial breatking, and small, dry, crepitant râle; and the discovery was often a source of great surprise and interest, that, with so few of the usual indications of serious disease, so much of the lung had been already disabled.

Chathein, January, 1854

\section{RECOVERY AFTER TAKING A LARGE DOSE OF HYDROCYANIC ACID.}

By W. M. BURMAN, Esq., M.R.C.S.E., Wath-upon-Dearne.

THE occurrence I am about to relate took place on August 6 th, 1853, at six P.M.; but before going into detail, I must premise that my father and myself are practising together and use the same surgery. We keep our scheele's hydrocyanic acid for dispensing much diluted,-namely, in the proportion of one minim of the acid to a fluid drachm of water; this is kept in a four-ounce purple glass bottle. It so happened that a short time previously we had received a fresh supply of Scheele's acid in a bottle precisely similar to the one in which we keep our very dilute acid. This strong acid was put into a cupboard under lock and key, but on the day in question had been taken out to replenish the dispensing bottle, and then left on the surgery counter. Soon afterwards my father returned from his afternoon ride, and being troubled with slight dyspepsia, went into the surgery, as was his habit, and mixed himself a draught containing a little aromatic spirit of ammonia and bicarbonate of soda in two ounces of water, adding to it a fluid drachm of the very dilute acid, as he thought, but he took it ont of the bottle of Scheele's acid standing on the counter. He crank this off, noticing nothing peculiar in the taste. In a few seconds afterwards, upon looking at the bottle, he thought the label appeared cleaner than usual, and the idea fiashed on his mind that perhaps he had taken the strong acid. A glance at the proper dispensing bottle, which was in its place, confirmed this. He directly poured half an ounce of aromatic spirit of ammonia into the measure, and drank it, he believes without water, but he may have added some. He then walked into the house to the bottom of the stairs, (a distance of about sixteen yards), and called me; I came down stairs directly, and went into the surgery, where I found him standing at the counter with a glass measure in his hand. He said, "I have taken a drachm of that acid; what can be done?" adding, "I have since taken half an ounce of aromatic spirit of amfoonia." There was nothing in his appearance to attract my attention, but he spoke hurriedly, expiring deeply at the same time; he then sat dowa on a chair. I immediately put some crystals of snlphate of iron into a measure, adding one drachm of the tincture of the sesquichloride of iron, and one ounce of water, stirring the mixture rigorously, to get as many of the crystals dissolved as possible in the time, and gave it to him to drink, which he did. I had no liquor potassium at hand, or I should have added some to the mixture before giving it to him, to precipitate the mixed oxides of iron; as it was, I was obliged to trust to the ammonia he had taken. My object in giving him this was to endeavour to get the mixed oxides of iron in contact with at least part of the acid in the stomach, and thus to convert it into Prussian-hlue, as suggested by Messrs. Smith, of Edimburgh. Directly after drinking this, he began to breathe deeply, jassed his hand over his forehead and top of his heid, and said, "Oh, I feel very queer; had I not better go out of doors"? I said, "Yes," and with my assistance he staggered out, and dropped senseless in a sitting posture on a stone step at the surgery door. This was just about tuo minutes after taking the poison, as ascertained afterwards by going through the same routine. From this time he recollects nothing till twenty minutes afrerwards. His breatling was now slow and very deep; his ejes turned up completely under the upper lid; pulse moderate in volume, but very slow and internitting. I hastily took off his neckerchief, fetched a large pitcher of water, and poured it over the back of his head and down his back. This produced no apparent effect at the instant, but a few seconds aifter he romited a moutinful of glairy mucus. (This was nearly four minutes 
from the time of taking the poison.) I sent for another pitcher of water, and during the interval again examined the pulse, and fomd it slower than before, feeble, and threatening to stop altogether; respiration rery slow and deep, irregular, with blowing expiration and puffing of the cheeks; a little frothy mucus ran from his month. At this period the relaxation of the whole body was as great as that of a person recently dead. I now gave him another close of the iron mixture as before, adding a little aromatic spirit of ammonia. By spealing loudly, shaking him, and pouring it into his mouth, I got him to swallow the whole of it. Meantime the servant returned with another pitcher of water, (about four pints, which I instantly poured down his back, (five minutes after taking the poison.) This appeared to rouse him a little, and directly afterwards he romited sbout two ounces of a deep bluishgreen liquid; this I was glad to see, for I hoped that partial decomposition of the acid had taken place. The pulse and rcspiration were slightly quicker and more regular; pupils still quite invisible; conjunctiva injected; face livid. After an inspiration more than usually deep, he opened his moutl wide, and stretched out his arms; a spasmodic flutter passed over the face, and then over all the body, and I expected fully to hear a scream, as I had generally noticed in animals, or that he was about to have a convulsion; but just as it began to pass off, he romited twice, and seemed relieved by it. The vomited matter was still bluish-green, and this time mixed with pieces of half-digested meat, which had been taken at dinner, four hours previously. I next gave him two drachms of aromatic spirit of ammonia in one ounce of water, and with some difficulty got him to swallow it. Having again filled the pitcher, I poured the water down his back as before, and directly afterwards he vomited two or three times, (seven minutes from the time of taking poison.) The respiration and pulse were now very much better, the latter being quicker and pretty regular. Soon after the vomiting, I noticed a little movemen of the hands, apparently voluntary. I now hoped the imme diate danger was passed, (eight minutes,) so I watched the symptoms for a minute or two, and then the pulse beginning to falter a little, I gave lim two drachms of aromatic spirit of ammonia in one ounce of water, which, with a little difficulty, he swallowed. I tried to get him to speak, or to give any evidence that he understood what was said to him, but failed to elicit any sign of consciousness from him; still I considered him tolerably safe, for the pulse was pretty strong and regular, and the respiration, although deep, was quite regular; the countenance was also now regaining its natural anpearance, and that extreme flaccidity of the $1 \mathrm{imbs}$ was nearly gone. After about five minutes more had elapsed, (fifteen minutes,) he opened his eyes, and gave utterance to an ejaculation, and evidently understood, to some extent, what was said to him. Soon afterwards he complained of his trousers being wet, and this is the first circumstance that he remembers after leaving the surgery more than twenty minutes before. We presently got him into the house, and gave him a little hot brandy-andwater. I was now anxious to get him to bed as quickly as possible, judging that rest in the recumbent position would most conduce to his recovery. After sitting ten or fifteen minutes, he was able with great difficulty and with our assistance to walk up-stairs, but vomited several times during the transit. We got him into bed, and soon afterwards, turning to me, he said, "You shonld have used the cold affusion," and seemed quite surprised when I told him that I had done so pretty freely. During the evening, he took a simple effervescent iraught now and then, and presently he dropped asleep. He passed a good night, and next morning complained of pain across the loins, but was otherwise pretty well, except a feeling of general weakness. I ought to have mentioned that my father is about sixty years of ase, and of a strong constitution.

A day or two afterwards I analyzed the acid. I measured one drachm in the same two-ounce measure that my facher usel, and put it into a minim measure; it filled up to seventy minims. I diluted thus and then added a solution of nitrate of silver till no more precipitate was produced. I repeatedly washed this precipitate, and diled it carefully for a long time; but to make sure that it contained no more water, I put it into a warm oven for an hour, during which time it lost nearly one-fifth of a grain. It now weighed exactly twelve grains, which would be equal to $2 \cdot 4$ grains of anhydrou's hydrocyanic acid, the quantity my father took. As 100 grains of the acid filled up to 105 minims in the same small measure, this would give $3 \cdot 3$ as the per-centage of the anhyclrous acid in the Scheele"s acid used.

I have been thus minute, perhaps unnecessarily so, in the detail of this case because it presents many points of unusual interest; some of these it may be well to recapitulate very briefly:

1stly. This is the largest quantity recorded (so far as I know) after taking which recovery has ensued.

2ndly. The quantity of acid taken was measured, loing certainly no less than one drachm of scheele's strength (at $3 \cdot 3$ per cent.), and being equal to $2 \cdot 4$ grains of real acid.

Brdly. The time at which insensibility supervened after taking the poison is accurately known, namely tico minutcs. Lastly. The good effects of the cold afiusion, and the probable decomposition of part of the poison by the mixed oxides of iron.

\section{ON PASSIVE HEMORRHAGE FROM THE} KIDNEYS.

\section{By E. G. CROOKE, M.D. Edin., \&c., Chorley, Torkshire.}

OF the many phases of renal disease, there is one so in. sidious in its progress and indefinite in its characteristics, that although attention cannot but be drawn to the condition of the urinary organs, yet the exact locality of the disease is by no means evident. This arises from the obscure nature of the general symptoms; for as the local ones refer rather to the bladder than to the kidneys, the former may possibly be looked upon as the affected organ. Nioreover, the action of chemical reagents upon the urine secreted in this form of disease, and the average specific gravity and quantity of that fluid, give little aid in leading to an accurate diagnosis, unless the microscope be used to assist in the investigation, when the presence of blood corpuscles, epithelial cells, with occasional casts of uriniferous tubes, evidence that the kidneys themselves are suffering from some lesion, functional or organic. When the urine, upon the application of proper tests, clearly indicates the presence of albumen, and when the blood-globules are in such quantity as to colour that fiuid, and subside to the bottom of the containing vessel, there can be no doubt as to the existence of hrmorrhage, active or passive, from some part of the urinary organs, but this form of "passive hæmorrhage from the kidneys" is not so easily discerned.

Several cases of chronic hæmaturia having occurred in the practice of the writer, he ventures to bring their general history under notice, more especially as he has been induced to think it probable that this form of renal disease is much more frequent than is supposed, and that it is often the first stase or iorerunner of that condition in which free albumen is present in the urine-viz., of "chronic albuminous nephritis," and that when the "acute desquamative nephritis" following upon the exanthemata is supposed to have yielded to treatment, chronic hæmaturia is apt to remain, or to be induced upon the application of a slight exciting cause.

Symptoms. - Passive renal hæmorrhage offers to our notice two classes of symptoms-the general and the local. The generel are those of anemia, the result of a continual draining away of that vital fluid, the blood; the local refer chiefly to the bladder. The general symptoms are, a pallid complexion, of a dirty-white or muddy colour; with dilated pupils; occa sional headache and singing in the ears; the tongue is large, flabby, and furred, the edges thereor indented by the teeth, the bowels are open and loose; there is much fictulence and nausea, with irregular" appetite; palpitation is frequent; the surface of the body is cool; the skin soft and relaxed, but dry; the pulse full, soft, and bounding, or small and soft, pntting on the former condition upon change of posture; there is gradual but progressive emaciation, irritability, and gloominess of temper, with great disinclination to any exertion, bodily of mental. These symptoms vary in degree according to the longer or shorter duration of the disease.

2nd. The local symptoms are in some cases an aching pain in the loins, but this is, perhaps, rather: an exception than the rulc. They, the loins, are rather the seat of an uneasiness and feeling of weakness, which is increased upon pressure: the calls to mieturate are frequent and urgent, attended with pain sometimes referable to the juenis, sometimes to the inside of the thighs and to the perinxum; the urine is not much, if at all, increased in quantity when compared with the amount of fluids imbibed.

Pathological Indications of the Urine. The usual quantity of fiuids being taken into the stomach, the arerage daily amount of urine excreted may be stated at about fifty ounces. The specific gravity ranges from $10 \cdot 15$ to 10.55 , the latter being the standard of the urina sanguinis. A gradual reduction in the weight of the urine has been observed in those cases which have been attended with frequent relapses. The 